\title{
Microbial community composition in sediments resists perturbation by nutrient enrichment
}

\author{
Jennifer L Bowen ${ }^{1}$, Bess B Ward ${ }^{2}$, Hilary G Morrison ${ }^{3}$, John E Hobbie ${ }^{1}$, Ivan Valiela ${ }^{1}$, \\ Linda A Deegan ${ }^{1}$ and Mitchell L Sogin ${ }^{3}$ \\ ${ }^{1}$ The Ecosystems Center, Marine Biological Laboratory, Woods Hole, MA, USA; ${ }^{2}$ Department of Geosciences,

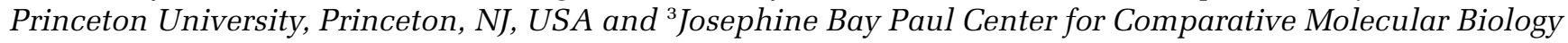 \\ and Evolution, Marine Biological Laboratory, Woods Hole, MA, USA
}

\begin{abstract}
Functional redundancy in bacterial communities is expected to allow microbial assemblages to survive perturbation by allowing continuity in function despite compositional changes in communities. Recent evidence suggests, however, that microbial communities change both composition and function as a result of disturbance. We present evidence for a third response: resistance. We examined microbial community response to perturbation caused by nutrient enrichment in salt marsh sediments using deep pyrosequencing of 16S rRNA and functional gene microarrays targeting the nirS gene. Composition of the microbial community, as demonstrated by both genes, was unaffected by significant variations in external nutrient supply in our sampling locations, despite demonstrable and diverse nutrient-induced changes in many aspects of marsh ecology. The lack of response to external forcing demonstrates a remarkable uncoupling between microbial composition and ecosystem-level biogeochemical processes and suggests that sediment microbial communities are able to resist some forms of perturbation.
\end{abstract}

The ISME Journal (2011) 5, 1540-1548; doi:10.1038/ismej.2011.22; published online 17 March 2011

Subject Category: microbial ecology and functional diversity of natural habitats

Keywords: salt marsh; eutrophication; estuaries; denitrification; resistance; nirS

\section{Introduction}

Estimates of the diversity of microbial communities have increased immensely in recent years, initially based on sequencing of clone libraries (Rappé and Giovannoni, 2003). Now, next-generation sequencing has provided genomic data from habitats all over the world (Sogin et al., 2006; Huber et al., 2007; Galand et al., 2009) and greatly increased estimates of species richness. Although there is considerable debate regarding absolute measures of diversity, it is clear that microbial communities support greater diversity than suggested by prior methodologies (Kunin et al., 2009; Huse et al., 2010). The role this diversity plays in microbial community structure, function and response to disturbance, however, is poorly understood. Allison and Martiny (2008) used a meta-analysis to determine the extent to which microbial communities demonstrated resistance, resilience or functional redundancy in the face of environmental perturbations. They showed that in most cases microbial communities were sensitive to

Correspondence: Present address: JL Bowen, Biology Department, University of Massachusetts Boston, Boston, MA 02125, USA.

E-mail: jennifer.bowen@umb.edu

Received 26 August 2010; revised 10 November 2010; accepted 3 February 2011; published online 17 March 2011 disturbance, regardless of the system or the nature of the disturbance (Allison and Martiny, 2008).

Among the disturbances included in the Allison and Martiny (2008) meta-analysis, the addition of inorganic nutrients induced a perturbation response in the greatest number of studies. Enrichment of natural ecosystems by inorganic nutrients, in particular nitrogen $(\mathrm{N})$, is occurring at an alarming rate and is fundamentally perturbing the global $\mathrm{N}$ cycle (Galloway et al., 2008). Such perturbations are particularly noticeable in the coastal zone where human population growth has increased the amount of anthropogenic $\mathrm{N}$ entering near-shore waters. High $\mathrm{N}$ loading alters coastal biogeochemistry via increased primary production and associated symptoms of eutrophication, including increased severity of harmful algal blooms (Paerl, 1997), decreased areas of seagrass beds and the commercially important species that rely on them (Valiela et al., 1992; Deegan, 2002) and expanded areas of anoxic dead zones (Rabalais et al., 2002; Osterman et al., 2008).

Wetland biogeochemical processes are critical for removing anthropogenic $\mathrm{N}$ before its entry into the coastal ocean. Salt marshes provide this ecosystem service by sequestering some portion of $\mathrm{C}$ and $\mathrm{N}$ inputs in increasing macrophyte biomass and accreting marsh peat (Brin et al., 2010), and by converting $\mathrm{N}$ to gaseous forms $\left(\mathrm{NO}, \mathrm{N}_{2} \mathrm{O}\right.$ and $\mathrm{N}_{2}$ ) via 
denitrification and, to a lesser extent, anammox (Hopkinson and Giblin, 2008). The importance of salt marsh biogeochemistry in ameliorating eutrophication is well recognized, but little attempt has been made to understand how the additional supply of $\mathrm{N}$ to these marshes is altering the structure of the sediment microbial communities responsible for this critical ecosystem service. We used two marsh nutrient enrichment experiments to test how increased nutrient supply altered the community composition of microbes, in particular those microbes responsible for key $\mathrm{N}$ loss processes in the marsh. Whether the microbial response to perturbation by nutrient enrichment is classified as resistant, resilient or functionally redundant has relevance for the ecological subsidy provided by salt marshes as well as for our understanding of the important connection between microbial community composition and biogeochemical function.

The two on-going fertilization experiments used in this study were designed to investigate how increased $\mathrm{N}$ supply alters the ecology of salt marsh ecosystems. Unintentional enrichments that resemble these experimental manipulations are being carried out in estuaries around the world that are experiencing moderate to severe increases in $\mathrm{N}$ loading. The two experiments examined here differ in the duration of the experiment and in the form and mechanism of nutrient delivery, but both experiments have documented wide-spread ecological responses to the nutrient perturbation
(Figure 1; Supplementary Table S1). Significant responses to fertilization are reported for sediments, food webs and for microbially mediated biogeochemical processes (Supplementary Table S1). Some of the well-documented changes to the marsh ecology include increases in $\% \mathrm{C}$ and $\% \mathrm{~N}$ content of the sediments, increases in rates of bacterial production and increases in microalgal and benthic invertebrate biomass (Supplementary Table S1). Many of the additional effects of nutrients resulted from changes in the keystone species of marsh vegetation, Spartina alterniflora. Increased nutrient inputs caused a shift from the short to the tall phenotype of S. alterniflora (Valiela et al., 1985) and accompanying this shift were well-documented changes in the redox chemistry of the sediments, including increased oxidation of the rooting zone (Howes et al., 1981). The extent to which fertilization led to changes in macrophyte distribution that then translated into changes in the plot-wide distribution of microbes was not addressed in this study. Rather, our interest was in explicitly testing community response to a single forcing function: nitrogen supply.

The experimental marsh enrichments and the previously documented changes in microbially mediated biogeochemistry of the ecosystem offer a unique opportunity to examine whether chronic exposure to increased nutrient supply alters the structure and function of the marsh sediment microbial community. We used two approaches to

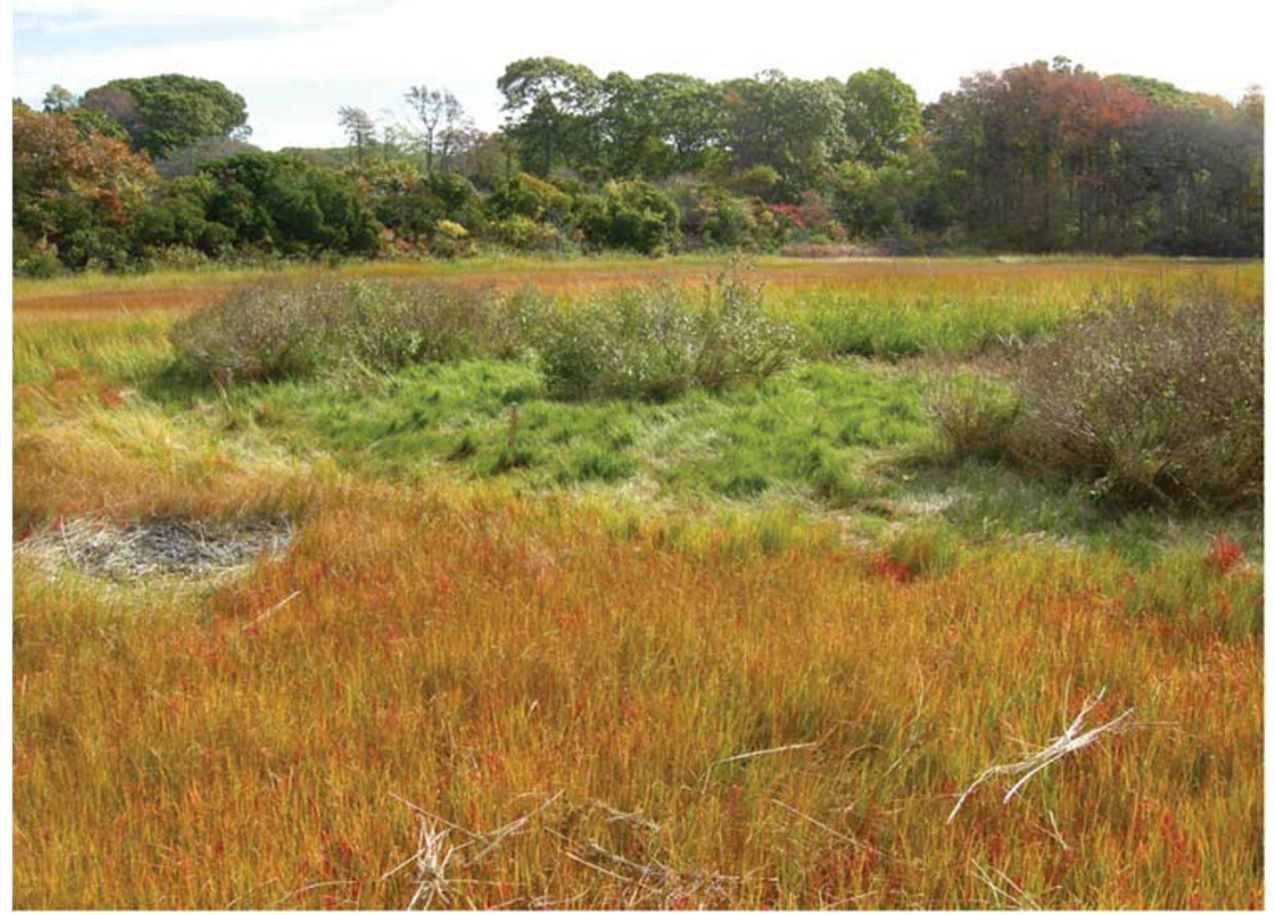

Figure 1 Photograph of a very highly fertilized plot at GSM taken autumn 2007. The fertilized plot is clearly visible in the center of the photograph and is surrounded by unfertilized marsh that has begun fall senescence. Note the difference in macrophyte community composition, above ground biomass and elevation between the fertilized and unfertilized portions of the marsh. Photo by I Valiela. 
assess this perturbation effect. First, we used pyrosequencing to catalog the taxonomic richness and relative abundance of microbes in the two replicated fertilization experiments. Second, we used microarray analysis of the same samples to investigate a key functional gene involved in salt marsh nitrogen cycling. As denitrification is the primary $\mathrm{N}$ loss mechanism in these marshes (KoopJakobsen and Giblin, 2010), we examined perturbation-induced changes to the diversity and relative abundance of nirS, a key gene in the denitrification pathway. This combination of methods applied to two different enrichment experiments, both of which are replicated, provides the most robust assessment to date of the microbial community response to perturbation.

\section{Materials and methods}

\section{Site descriptions}

The on-going fertilization experiment located at the Plum Island Ecosystem (PIE) Long-Term Ecological Research Station in eastern Massachusetts (42.759 $\mathrm{N}, 70.891 \mathrm{~W})$. Within PIE two pairs of marshes within the Rowley River marsh complex were selected based on similarities in standing stocks of benthic microalgae, vascular plant community composition, hydrology and nutrient dynamics (Deegan et al., 2007). One marsh in each pair (Sweeney marsh in marsh pair one (West/Sweeney marshes) and Clubhead marsh in marsh pair two (Nelson/ Clubhead marshes)) began receiving fertilizer additions in 2004. In the fertilized marsh, $\mathrm{NO}_{3}^{-}$and $\mathrm{PO}_{4}^{3-}$ were diluted into flooding marsh creek water on every high tide through the growing season to attain marsh-wide concentrations of $70 \mu \mathrm{M} \mathrm{NO}{ }_{3}^{-}$and $4 \mu \mathrm{M}$ $\mathrm{PO}_{4}^{3-}$ (equivalent to a loading rate of $0.6 \mathrm{~g} \mathrm{~N} \mathrm{~m}^{-2}$ week $^{-1}$ ). These targets were chosen because they are roughly 15 -fold higher than the background nutrient concentrations in flood tide waters. Actual concentrations of $\mathrm{N}$ delivered to the sediments varied across the surface of the marsh but averaged $80 \mu \mathrm{M}$ (range: $49-105 \mu \mathrm{M}$ ) in the fertilized marsh of the first marsh pair and averaged $50 \mu \mathrm{M}$ (range: $2-78 \mu \mathrm{M}$ ) in the fertilized marsh of the second pair (Deegan et al., 2007). This experimental design provides two different comparisons: (1) duplicate whole marsh enrichments that can be contrasted with specifically paired control marshes and (2) samples taken before the onset of fertilization compared with samples taken in the months following the initiation of the treatment. Further details of the experimental design have been reported elsewhere (Deegan et al., 2007).

The Great Sippewissett Marsh (GSM) experiment began in 1971 in Falmouth Massachusetts (41.5828 N, $70.6397 \mathrm{~W}$ ). Four treatment levels were randomly assigned to duplicate $10 \mathrm{~m}$ diameter plots (eight plots total). Each plot was selected to encompass a creek terminus to ensure that the distribution of habitats within each plot would be similar. Since 1971, these plots have been fertilized by the biweekly addition of pelletized sewage sludge in the following concentrations: $\mathrm{C}$ (control): no sewage sludge added, LF: $0.85 \mathrm{~g} \mathrm{~N} \mathrm{~m}^{-2}$ week $^{-1}$, HF: $2.52 \mathrm{~g} \mathrm{~N}^{-1}$ $\mathrm{m}^{-2}$ week $^{-1}$ and XF: $7.46 \mathrm{~g} \mathrm{~N} \mathrm{~m}^{-2}$ week $^{-1}$. Thus, this experiment allows for the comparison of duplicate plots that receive a range of nutrient inputs that spans an order of magnitude, and are considerably more highly loaded than the PIE experiment. Moreover, these plots have been receiving the treatment for nearly 40 years so the microbial community has had sufficient time to adjust to the perturbation. Further details of the experimental design have been reported elsewhere (Valiela et al., 1973, 1975).

\section{Sample collection and DNA extraction}

Sediments from both experiments were collected using a sterile $15 \mathrm{~mm}$ diameter syringe corer and were taken from surface sediments $(<1 \mathrm{~cm}$ depth) within the rooting zone of the tall ecotype of S. alterniflora. In the PIE experiment sediments were collected in May (before the onset of that season's fertilization), June, August and September of 2005 and at GSM sediments were collected in September 2007. Ten cores were taken from sediments at each site, combined and mixed in sterile $20 \mathrm{ml}$ scintillation vials, and stored on ice until arrival at the laboratory. We initially hypothesized that homogenizing multiple samples from a single site would minimize local-scale variability although tests of this hypothesis indicate that homogenized samples and single samples capture the same snapshot of the community (Bowen et al., in preparation). Aliquots of homogenized sediments were removed with a sterile spatula and were stored frozen at $-80^{\circ} \mathrm{C}$ until extraction. The remaining sediments were used to measure bacterial production (Bowen et al., 2009), nitrogen fixation, following the methods of Tyler et al. (2003), and the carbon and nitrogen content of the sediments using a PerkinElmer model 2400 CHN analyzer (PerkinElmer Inc., Waltham, MA, USA). DNA was extracted from triplicate aliquots of sediments using the PowerSoil DNA extraction kit (MoBio Laboratories, Carlsbad, CA, USA) following manufacturer's instructions. Presence of DNA was confirmed by gel electrophoresis and DNA from the triplicate extractions were pooled and stored at $-80^{\circ} \mathrm{C}$ for further use.

\section{Pyrosequencing analysis}

Pyrosequencing methodology has been described in detail (Sogin et al., 2006; Huber et al., 2007; Huse et al., 2007, 2008, 2010; Galand et al., 2009). Briefly, the hypervariable V6 region of 16S rRNA was amplified using a combination of nine forward and reverse primers that are thought to amplify most known bacteria. Sequence adaptors of five base 
oligonucleotides were attached to the primer set used with each sample, thereby allowing for postsequencing bioinformatic separation of the samples (Huber et al., 2007). Amplified DNA was spin column purified using the MinElute PCR purification kit (Qiagen, Valencia, CA, USA) and was quantified on a Bioanalyzer 2100 (Agilent, Palo Alto, CA, USA). Purified DNA was then sequenced on a Roche GSFLX pyrosequencer (Roche Applied Science, Indianapolis, IN, USA) following the methods outlined in Sogin et al. (2006) and Huber et al. (2007). Sequence data were then subject to rigorous quality control checks as described in Huse et al. (2007, 2008). Operational taxonomic units (OTUs) of sequence tags were assigned based on a $2 \%$ single linkage pre-clustering using a pairwise alignment followed by a $3 \%$ average linkage clustering (Huse et al., 2010). All V6 sequence data are available at the VAMPS database (http://vamps. mbl.edu/) and in the NCBI short read archive (accession no. SRP004028).

\section{Microarray analysis}

The nirS microarray consists of 39 90-mer oligonucleotide probes that contain a 70-mer region complementary to a portion of the nirS gene and a 20-mer control region that is bonded to a CMT-GAPS aminosilane-coated glass slide (Corning Inc., Corning, NY, USA). Probe selection was based on an algorithm to select archetypes that hybridize with sequences that are $\geqslant 85 \%$ identical to the probe sequence and was generated from a combination of known and environmental nirS sequences present in the public databases when the array was designed (Bulow et al., 2008). DNA hybridization targets (256 bp) were generated from triplicate PCR products using primers nirS1F and nirS3R (Braker et al., 1998). After amplification, PCR products were pooled and purified with the QIAquick PCR purification kit (Qiagen). PCR products were then labeled using the Klenow enzyme and hybridized to the array following standard methods (Ward et al., 2007; Bulow et al., 2008). After hybridization, the slides were washed (Ward et al., 2007) and scanned on an Agilent Laser Scanner (Agilent Technologies, Palo Alto, CA, USA).

Scanned images of the slide were analyzed with Gene Pix Pro (version 6.0, Molecular Devices, Sunnyvale, CA, USA) and analyzed in Microsoft Excel. Each slide contains eight arrays and each array consists of four replicate blocks. Data were quality checked (Ward et al., 2007; Bulow et al., 2008) and then the fluorescence from the Cy3-bound nirS sequences were compared with the Cy5 fluorescence to determine the fluorescence ratio for each probe after background fluorescence was subtracted. The Cy3/Cy5 ratios were first normalized for variations in fluorescence intensities across the slide by comparing Cy3/Cy5 fluorescence from internal standards within each array. Next, we calculated the relative fluorescence ratio (RFR) by comparing the fluorescence ratio of any one probe to the total fluorescence across all probes within a given block. The four RFR for each probe within an array (one from each block) were then averaged to derive a mean RFR for each probe that could be compared among samples on different slides. Microarray data are archived at the NCBI Gene Expression Omnibus (accession no. GSE25227).

\section{Quantitative PCR}

Quantitative PCR (qPCR) was performed on DNA extracts from the GSM-fertilized plots. nirS and 16S rRNA standards were quantified using Quant-iT Picogreen (Molecular Probes Inc., Eugene, OR, USA) and serially diluted to generate known standards. Environmental DNA from each plot was amplified in triplicate, along with triplicate standards and internal controls, on a Strategene MX-3000 (Stratagene, La Jolla, CA, USA) under the following conditions: $16 \mathrm{~S}$ rRNA was amplified following the protocol outlined in Biddle et al. (2008). For each sample of $16 \mathrm{~S}$ rRNA, $1.125 \mu \mathrm{l}$ of $20 \mathrm{mM}$ primers $357 \mathrm{~F}$ and 519R was added along with $1 \mu \mathrm{l}$ DNA, $12.5 \mu \mathrm{l}$ SybrGreen master mix (Applied Biosystems, Carlsbad, CA, USA) and $10.5 \mu \mathrm{l}$ deionized water. They were amplified with a 10 -min initial denaturing step at $95{ }^{\circ} \mathrm{C}$ followed by 40 cycles of $95^{\circ} \mathrm{C}$ for $30 \mathrm{~s}, 60^{\circ} \mathrm{C}$ for $1 \mathrm{~min}$ and $72^{\circ} \mathrm{C}$ for $1 \mathrm{~min}$. All amplification products were checked for quality by examination of melt curves and by gel electrophoresis. The nirS gene was amplified following the method of Jayakumar et al. (2009). Briefly, $0.5 \mu \mathrm{l}$ of $100 \mathrm{mM}$ primers (nirS1F and nirS3R (29)), $1 \mu \mathrm{l}$ of DNA, $12.5 \mu \mathrm{l}$ of SybrGreen master mix (Applied Biosystems) and $10.5 \mu \mathrm{l}$ deionized water were amplified using the following conditions: $95{ }^{\circ} \mathrm{C}$ for $15 \mathrm{~min}$, followed by 40 cycles of $94{ }^{\circ} \mathrm{C}$ for $15 \mathrm{~s}, 62^{\circ} \mathrm{C}$ for $30 \mathrm{~s}$ and $72{ }^{\circ} \mathrm{C}$ for $30 \mathrm{~s}$. Again, amplification products were checked for quality by examining melt curves and gel electrophoresis of the amplification products.

\section{Statistical analyses}

Pyrosequencing analysis provides data on both the composition and relative abundance of OTUs in each sample thereby making it possible to analyze whether particular members of the microbial community are either stimulated or inhibited by nutrient enrichment. If either stimulation or inhibition were to occur as a result of the treatment then the abundance of a given OTU in fertilized marshes would deviate from the abundance of that same OTU in control marshes to a greater extent than would be expected by chance. To analyze the pyrosequencing data, we used a Wilcoxon MannWhitney test (aka Mann-Whitney $U$-test) to determine whether the distribution of OTUs differed as a result of the treatment in both the PIE and GSM experiments. Rejection of the null hypothesis in 
these tests would indicate that chance alone cannot explain the distribution in the OTUs. The Wilcoxon Mann-Whitney tests were performed using the freeware statistical program R (http://cran.r-project. $\operatorname{org} /$ ).

To analyze the nirS microarray data, the RFRs from each sample were arcsine transformed and analysis of variance was performed to test for a significant treatment effect in each experiment. In the PIE experiment, this was done by comparing the RFR from the two unfertilized marshes with the RFR from the two fertilized marshes in each month of the fertilization. For GSM this was done by comparing the RFR of the control plots compared with each of the treatment plots. Furthermore, for GSM we used analysis of variance to test the treatment effect on the number of nirS genes present in the control vs. treatment plots as determined by qPCR. All analysis of variance tests were performed using $R$.

\section{Results and discussion}

We compared between 20000 and 25000 pyrosequences per site from bacterial DNA extracted from sediments of multiple fertilized and control marsh plots at both PIE and GSM. This degree of sequencing is 20-25 times deeper than is typical of clone library studies and provides the most robust examination of microbial response to perturbation to date. Furthermore, cumulative frequency distribution curves suggest that sampling to this depth captures all the dominant taxa present in the sample (Bowen et al., in preparation).

In both marsh experiments, we controlled for variations in microbial communities induced by the dominant vegetation or elevational gradients in the marsh by sampling from sediments found only in the zone dominated by the tall phenotype of S. alterniflora. The extent to which fertilization altered the microbial community associated with other marsh habitats was not addressed in this study, however, prior DNA fingerprinting work indicates that the fertilization effect in other habitats was also very small (Bowen et al., 2009). To test the effect of increasing nutrient supply on the structure of the microbial community in the PIE experiment, we compared the number of times an OTU was identified within each marsh pair (Figure 2). If each OTU was present in equal numbers in the control and fertilized marsh of marsh pair one then each point, representing an individual OTU, would fall exactly on a 1:1 line (Figure 2, top). Because of incomplete sequencing of the microbial community, exact adherence to the 1:1 line would not be expected, rather there would be some variance around the line that would be expected to occur solely by chance. Any effect of treatment would be detected by a deviation from the 1:1 line that is greater than could be predicted by chance alone. However, no such treatment effect was detected in either marsh pair one (Figure 2, top: $U=0.107$,
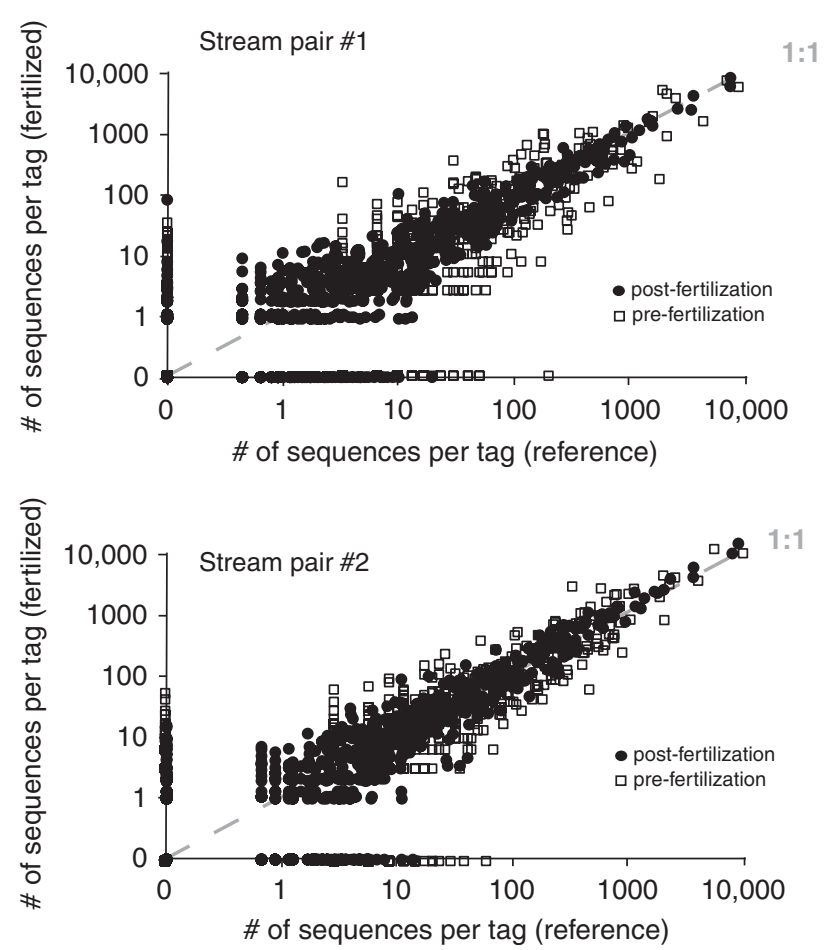

Figure 2 Number of sequences from different microbial taxa in control and fertilized marshes at PIE. Top: marsh pair one compares Sweeney (fertilized) with West (control). Bottom: marsh pair two compares Clubhead (fertilized) and Nelson (control).

$P=0.915$ ) or marsh pair two (Figure 2, bottom: $U=-0.668, P=0.504)$. Further evidence that the distribution of points around the 1:1 line can be attributed entirely to chance can be found by comparing the OTU distribution before the onset of fertilization (open squares), where no treatment effect should be detected, with the distribution of OTUs in the months following fertilization (closed circles). The similar variation in the two groups of samples provides another indication that the microbial community structure in these two PIE marsh pairs are largely unaffected by nutrient enrichment.

The GSM plots, fertilized at rates up to 10-fold higher and for decades longer than the PIE experiment, provide further evidence of microbial resistance to nutrient enrichment. As with the PIE fertilization (Figure 2), OTU abundance in the GSM sediment microbial community was neither stimulated nor inhibited by fertilization, regardless of the dose of fertilizer added (Figure 3). The distribution of OTUs when comparing the duplicate control plots to the lowest dose fertilized plots (fertilized at roughly similar rates to the marshes in the PIE experiment) do not deviate from one another more than can be explained by chance (Figure 3, top: $U=1.065, P=0.287$ ). Similarly, comparing OTU data from the two control plots with the two HF plots indicate no significant effect of fertilization (Figure 3, middle: $U=0.771, P=0.441$ ) and the same is true for the most highly fertilized plots (Figure 3, bottom: $U=0.745, P=0.456$ ). The lack of 


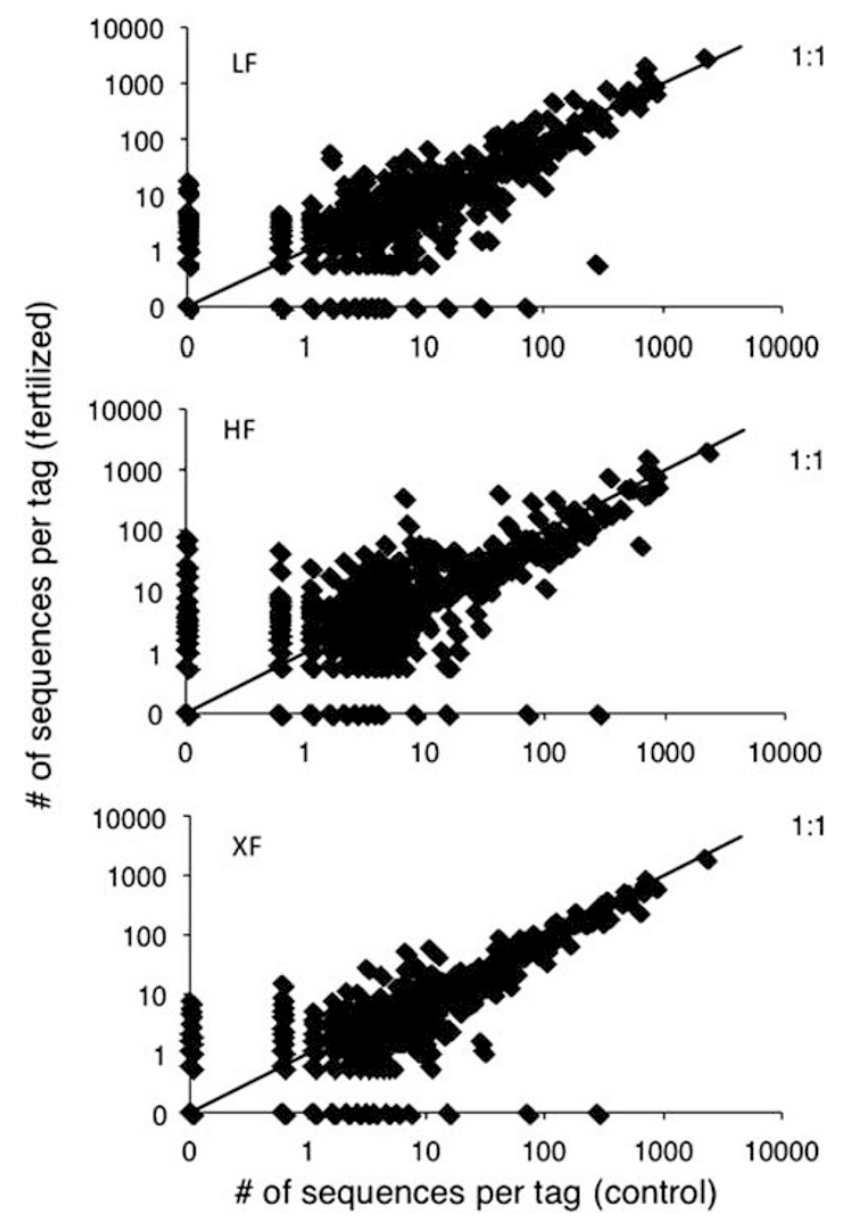

Figure 3 Number of sequences from different microbial taxa in $\mathrm{C}$ compared with LF (top), HF (middle) and XF (bottom) from GSM.

response by the microbial community is all the more surprising in light of the dramatic treatmentinduced changes that have occurred to both the biogeochemistry and ecology of these highly fertilized plots (Supplementary Table S1; Figure 1). Both the two marsh pairs in the PIE experiment and the more intensively fertilized GSM plots provide evidence that marsh sediment microbial communities, at least within the dominant $S$. alterniflora habitat, are resistant to nutrient-induced perturbation, in spite of measurable differences to other ecosystem components across a broad range of $\mathrm{N}$ loads.

The possibility remains that microorganisms may respond to perturbation through physiological adaptation within some functional genes that may not be detectable by examination of 16S rRNA alone. One functional gene likely to reflect changes in $\mathrm{N}$ transformations as a result of $\mathrm{N}$ fertilization is nirS, the gene that encodes the denitrification enzyme that catalyzes the reduction of $\mathrm{NO}_{2}^{-}$to $\mathrm{NO}$ (Zumft, 1997). Denitrification is a critical biogeochemical pathway in salt marshes because it removes landderived $\mathrm{N}$ before it enters coastal waters and stimulates eutrophication. In both marshes rates of denitrification have increased as a result of nutrient enrichment. At PIE, fertilized creek bottom sediments had denitrification rates that were $47 \%$ higher $(P=0.013)$ than control marshes (KoopJakobsen and Giblin, 2009). At GSM, there was a net stimulation of coupled nitrification-denitrification as a result of fertilizer inputs, with late summer rates ranging from 0 to $12 \mathrm{mmol} \mathrm{N} \mathrm{m}^{-2}$ day $^{-1}$ in control plots and 48 to $69 \mathrm{mmol} \mathrm{N} \mathrm{m}{ }^{-2}$ day $^{-1}$ in fertilized plots (Hamersley and Howes, 2005).

We used the RFR from the functional gene microarray (Ward et al., 2007; Bulow et al., 2008) to quantify the relative contribution of each archetype to the total nirS signal and determine the distribution of nirS-containing phylotypes in both the PIE and GSM marshes. The RFR for the 39 archetypes found in both marshes was remarkably consistent, with only minor differences as a result of fertilization in the GSM experiment, and no differences as a result of fertilization in the PIE experiment (Figure 4). The archetype CB2-S-138 dominated the nirS community in all marshes. In the GSM plots, only 2 of the 39 archetypes ( $~ 5 \%$ ) demonstrated a significant change in signal intensity as fertilizer dose increased (Supplementary Figure S1). The second strongest hybridization signal after archetype CB2-S-138, identified by archetype probe CB3-S-15, was negatively correlated with N supply and one minor archetype, CB3-S-102, appeared to increase with $\mathrm{N}$ supply in the GSM plots (Supplementary Figure S1). The remaining 37 archetypes, however, showed no difference in RFR as a result of fertilization in either set of experiments. The remarkable consistency in nirS community composition among the marshes and the stability of those communities in the face of considerable perturbation stands in contrast to the spatially variable community of denitrifiers found in the Chesapeake Bay using the same microarray (Bulow et al., 2008).

Functional gene microarrays can only detect relative changes in archetype abundance, not absolute differences (Ward et al., 2007). Quantitative PCR amplification using primers that quantify the total nirS abundance that is represented on the array, however, indicated that there was no increase in the absolute abundance of the nirS genes among the plots (Figure 5), implying that an increase in cell number cannot explain the apparent disconnect between the reported increase in rates of denitrification and the lack of response among denitrifiers represented by the microarray. Microorganisms must thus be responding to nutrient enrichment by altering their gene expression without concomitant changes in their community composition. The possibility remains that there were unknown denitrifiers present that are not represented on the microarray. In silico testing of the current array against nirS sequences published since its design shows that by far most, if not all, of the newly published estuarine sequences would be covered by the probe set used in this study. Interestingly, the 


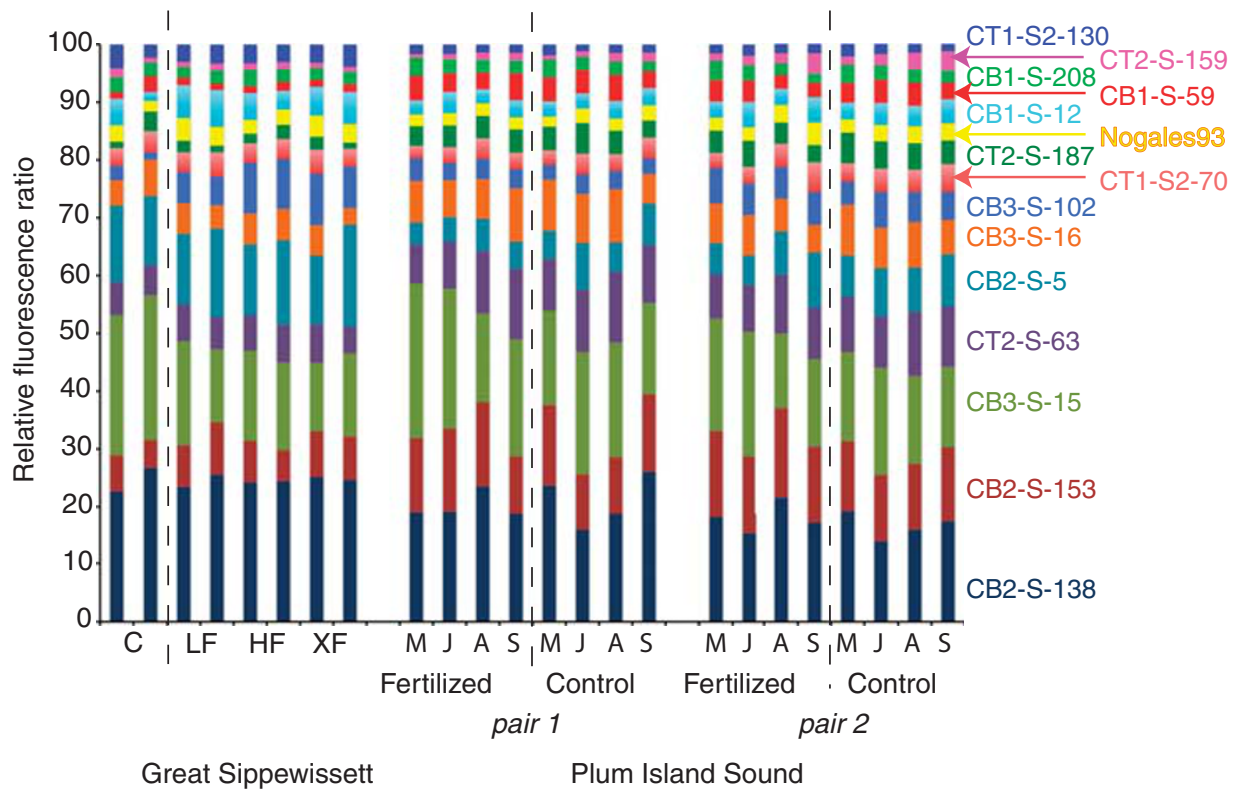

Figure 4 Stacked bar plot of the magnitude of the hybridization signal of the 15 most abundant nirS targets from GSM and PIE. The RFR indicates the relative signal strength of that archetype in each sample. Analysis of variance results indicate no significant differences between control and fertilized marshes in either experiment (GSM: $F=0.846, P=0.471$; PIE: $F=0.115, P=0.734$ ).

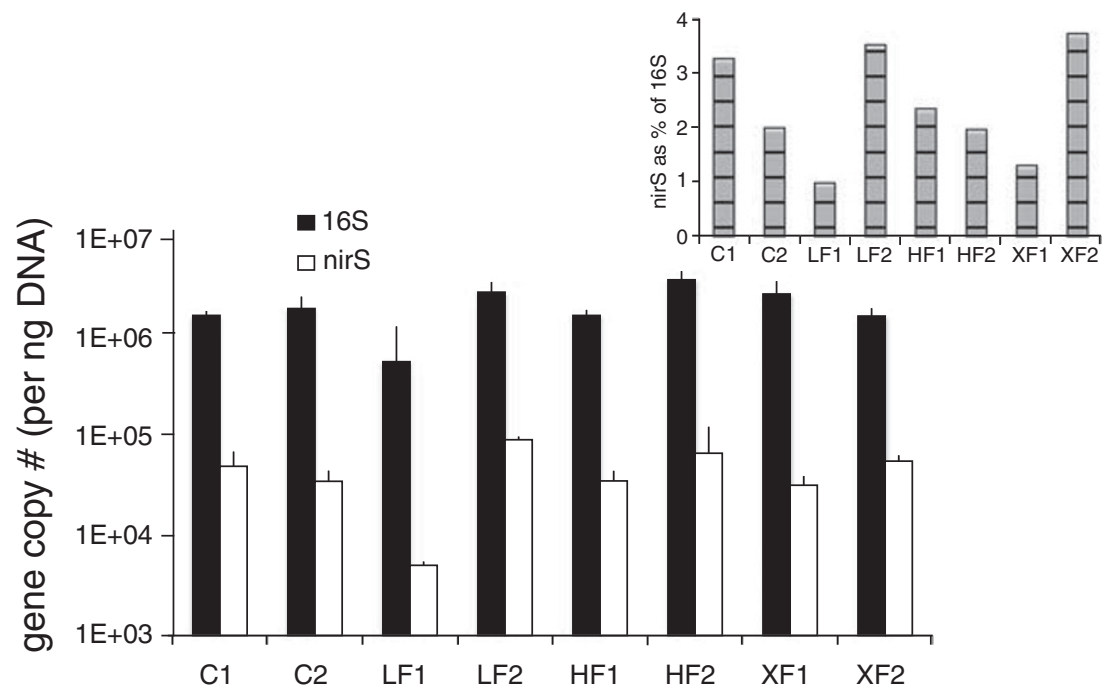

Figure 5 Quantitative PCR results comparing the absolute abundance of nirS genes in DNA from each of the GSM plots with the absolute abundance of the $16 \mathrm{~S}$ rRNA genes in the same plots. Inset: the $\%$ of $16 \mathrm{~S}$ rRNA that is nirS. There were no significant differences among treatments with respect to gene copy number for either $16 \mathrm{~S}(F=1.11, P=0.37)$ or nirS $(F=0.08, P=0.96)$, although the difference between the abundance of nirS and $16 \mathrm{~S}$ were clearly different from each other $(F=91.07, P<0.01)$.

major groups identified in clone libraries from estuaries in China, for example, are well represented in the estuarine probes on the current array. It seems unlikely, but difficult to test, that denitrifiers not represented on the array had varying and contradictory responses to the nutrient perturbation, compared with the major estuarine clades whose relative contributions to the assemblage were measured here.

The data presented here, therefore, robustly demonstrate that microbial community composition and relative abundance are both largely unaffected by additions of $\mathrm{N}$ and by indirect $\mathrm{N}$ induced ecological changes in the marsh habitat that we sampled. We showed this both by examining the distribution of OTU abundance in replicated experiments in Plum Island Sound and in replicated marsh plots at Great Sippewissett Marsh as well as by microarray analysis of the nirS functional gene that is a key component of the nitrogen cycle. A similar resistance by the microbial community to increased nutrient supply has been reported in salt marsh 
fertilization experiments in which researchers examined the phospholipid fatty acid structure of the bulk microbial community (Lovell et al., 2001) and the structure of the diazatrophs in the marsh sediments (Bagwell and Lovell, 2000). It is difficult to reconcile the remarkable consistency within the microbial community with the multitude of documented changes observed in other aspects of the marsh ecology in both systems (Figure 1; Supplementary Table S1), particularly with regard to the consistency within the denitrifying community. Studies that simultaneously assess rates of denitrification and expression of key $\mathrm{N}$ cycling genes such as nirS are needed to shed light on the apparent disconnect between the microbial community composition and biogeochemical function, as well as how both respond to environmental perturbation. The evidence presented here, however, suggests that microbial communities can show a greater degree of resistance to perturbation than has previously been demonstrated. The surprising resistance of these microbial communities suggests a difference between sediment and aquatic systems, the latter showing regular patterns of change with changing environmental conditions (Fuhrman et al., 2006, 2008; Crump et al., 2009), and indicates that there is much to be learned about the relationship between microbial community composition and ecological function.

\section{Conflict of interest}

The authors declare no conflict of interest.

\section{Acknowledgements}

Funding for this research came from NSF (DEB-0717155 to JEH, DBI-0400819 to JLB). Support for the sequencing facility came from NIH and NSF (NIH/NIEHS-P50ES012742-01 and NSF/OCE 0430724-J Stegeman PI to HGM and MLS, and WM Keck Foundation to MLS). Salary support provided from Princeton University Council on Science and Technology to JLB. Support for development of the functional gene microarray provided by NSF/ OCE99-081482 to BBW. The Plum Island fertilization experiment was funded by NSF (DEB 0213767 and DEB 0816963). The original Great Sippewissett marsh fertilization experiment was a collaboration between I Valiela and John Teal. Brian Howes and Dale Goehringer maintained the fertilization of the Great Sippewissett plots in recent years. Recent funding for maintenance of the Great Sippewissett Marsh Plots came from NSF (OCE-0453292, DEB-0516430 to IV). We would like to thank anonymous reviewers for constructive feedback on earlier versions of this manuscript.

\section{References}

Allison SD, Martiny JBH. (2008). Resistance, resilience, and redundancy in microbial communities. Proc Natl Acad Sci USA 105: 11512-11519.
Bagwell CE, Lovell CR. (2000). Persistence of selected Spartina alterniflora rhizoplane diazotrophs exposed to natural and manipulated environmental variability. Appl Environ Microbiol 66: 4625-4633.

Biddle JF, Fitz-Gibbon S, Schuster SC, Brenchley JE, House CH. (2008). Metagenomic signatures of the Peru Margin subseafloor biosphere show a genetically distinct environment. Proc Natl Acad Sci USA 105: 10583-10588.

Bowen JL, Crump BC, Deegan LA, Hobbie JE. (2009). Increased supply of ambient nitrogen has minimal effect on salt marsh bacterial production. Limnol Oceanogr 54: 713-722.

Braker G, Fesefeldt A, Witzel KP. (1998). Development of PCR primer systems for amplification of nitrite reductase genes (nirK and nirS) to detect denitrifying bacteria in environmental samples. Appl Environ Microbiol 64: 3769-3775.

Brin LD, Valiela I, Goehringer D, Howes B. (2010). Nitrogen interception and export by experimental salt marsh plots exposed to chronic nutrient. Mar Ecol Prog Ser 400: 3-17.

Bulow SE, Francis CA, Jackson GA, Ward BB. (2008). Sediment denitrifier community composition and nirS gene expression investigated with functional gene microarrays. Environ Microbiol 10: 3057-3069.

Crump BC, Peterson BJ, Raymond PA, Amon RMW, Rinehart A, McClelland JW et al. (2009). Circumpolar synchrony in big river bacterioplankton. Proc Natl Acad Sci USA 106: 21208-21212.

Deegan LA. (2002). Lessons learned: the effects of nutrient enrichment on the support of nekton by seagrass and salt marsh ecosystems. Estuar Coasts 25: 727-742.

Deegan LA, Bowen JL, Drake D, Fleeger JW, Friedrichs CT, Galván KA et al. (2007). Susceptibility of salt marshes to nutrient enrichment and predator removal. Ecol Appl 17: S42-S63.

Fuhrman JA, Hewson I, Schwalbach MS, Steele JA, Brown MV, Naeem S. (2006). Annually reoccurring bacterial communities are predictable from ocean conditions. Proc Natl Acad Sci USA 103: 13104-13109.

Fuhrman JA, Steele JA, Hewson I, Schwalbach MS, Brown MB, Green JL et al. (2008). A latitudinal diversity gradient in planktonic marine bacteria. Proc Natl Acad Sci USA 105: 7774-7778.

Galand PE, Casamayor EO, Kirchman DL, Lovejoy C. (2009). Ecology of the rare microbial biosphere of the Arctic Ocean. Proc Natl Acad Sci USA 106: 22427-22432.

Galloway JN, Townsend AR, Erisman JW, Bekunda M, Cai Z, Freney JR et al. (2008). Transformation of the nitrogen cycle: recent trends, questions, and potential solutions. Science 320: 889-892.

Hamersley MR, Howes BL. (2005). Coupled nitrificationdenitrification measured in situ in a Spartina alterniflora marsh with a ${ }^{15} \mathrm{NH}^{+}$tracer. Mar Ecol Prog Ser 299: 123-135.

Hopkinson CS, Giblin AE. (2008). Nitrogen dynamics of coastal salt marshes. In: Capone D, Bronk D, Mulholland M, Carpenter E (eds.), Nitrogen in the Marine Environment. Elsevier: Oxford, pp. 931-1036.

Howes BL, Howarth RW, Teal JM, Valiela I. (1981). Oxidation-reduction potentials in a salt marsh: spatial patterns and interactions with primary production. Limnol Oceanogr 26: 350-360.

Huber JA, Mark Welch DB, Morrison HG, Huse SM, Neal PR, Sogin ML. (2007). Microbial population structures in the deep marine biosphere. Science 318: 97-100. 
Huse SM, Dethlefsen L, Huber JA, Mark Welsh DB, Relman DA, Sogin ML. (2008). Exploring microbial diversity and taxonomy using SSU rRNA hypervariable tag sequencing. PLoS Genet 4: e1000255.

Huse SM, Huber JA, Morrison HG, Sogin ML, Mark Welch DB. (2007). Accuracy and quality of massively parallel DNA pyrosequencing. Gen Biol 8: R143.

Huse SM, Mark Welch DB, Morrison HG, Sogin ML. (2010). Ironing out the wrinkles in the rare biosphere through improved OTU clustering. Environ Microbiol 12: 1889-1898.

Jayakumar A, Naqvi SWA, Ward BB. (2009). Distribution and relative quantification of key genes involved in fixed nitrogen loss from the Arabian Sea oxygen minimum zone. In: Hood, RR (ed.), Indian Ocean Biogeochemical Processes and Ecological Variability. American Geophysical Union, pp. 187-203.

Koop-Jakobsen K, Giblin AE. (2009). Anammox in tidal marsh sediments: the role of salinity, nitrogen loading, and marsh vegetation. Estuar Coasts 32: 238-245.

Koop-Jakobsen K, Giblin AE. (2010). The effect of increased nitrate loading on nitrate reduction via denitrification and DNRA in salt marsh sediments. Limnol Oceanogr 55: 789-802.

Kunin V, Engelbrektson A, Ochman H, Hugenholtz P. (2009). Wrinkles in the rare biosphere: pyrosequencing errors lead to artificial inflation of diversity estimates. Environ Microbiol 12: 118-123.

Lovell CR, Bagwell CE, Czákó M, Márton L, Piceno YM, Ringerling DB. (2001). Stability of a rhizosphere microbial community exposed to natural and manipulated environmental variability. FEMS Microbiol Ecol 38: $69-76$.

Osterman LE, Poore RZ, Swarzenski PW. (2008). The last 1000 years of natural and anthropogenic low oxygen bottom water on the Louisiana Shelf Gulf of Mexico. Mar Micropaleo 66: 291-303.

Paerl HW. (1997). Coastal eutrophication and harmful algal blooms: importance of atmospheric deposition and groundwater as 'new' nitrogen and other nutrient sources. Limnol Oceanogr 42: 1154-1165.

Rabalais NN, Turner RE, Wiseman WJ. (2002). Gulf of Mexico hypoxia: AKA, 'The Dead Zone'. Ann Rev Ecol Syst 33: 235-263.

Rappé MS, Giovannoni SG. (2003). The uncultured microbial majority. Ann Rev Microbiol 57: 369-394.

Sogin ML, Morrison HG, Huber JA, Mark Welch DB, Huse SM, Neal PR et al. (2006). Microbial diversity in the deep sea and the underexplored 'rare biosphere'. Proc Natl Acad Sci USA 103: 12115-12120.

Tyler AC, Mastronicola TA, McGlathery KJ. (2003). Nitrogen fixation and nitrogen limitation of primary production along a natural marsh chronosequence. Oecologia 136: 431-438.

Valiela I, Foreman K, LaMontagne M, Hersh D, Costa J, Peckol P et al. (1992). Couplings of watersheds and coastal waters: sources and consequences of nutrient enrichment in Waquoit Bay, Massachusetts. Estuaries 15: $443-457$.

Valiela I, Teal JM, Cogswell C, Hartman J, Allen S, Van Etten R et al. (1985). Some long-term consequences of sewage contamination in salt marsh ecosystems. In: Godfrey PJ, Kaynor, ER, Pelczarski S, Benforado J (eds), Ecological Considerations in Wetlands Treatment of Municipal Wastewaters. Reinhold Co: New York, pp. 301-316.

Valiela I, Teal JM, Sass WJ. (1973). Nutrient retention in salt marsh plots experimentally enriched with sewage sludge. Estuar Coast Mar Sci 1: 261-269.

Valiela I, Teal JM, Sass WJ. (1975). Production and dynamics of salt marsh vegetation and the effects of experimental treatment with sewage sludge. J Appl Ecol 12: 973-981.

Ward BB, Eveillard D, Kirshtein JD, Nelson JD, Voytek MA, Jackson GA. (2007). Ammonia-oxidizing bacterial community composition in estuarine and oceanic environments assessed using a functional gene microarray. Environ Microbiol 9: 2522-2538.

Zumft WG. (1997). Cell biology and molecular basis of denitrification. Microbiol Mol Biol Rev 61: 533-616.

Supplementary Information accompanies the paper on The ISME Journal website (http://www.nature.com/ismej) 